\title{
Influence of Conventional Fermentation on Antioxidant Activity and Phenolic Contents of Two Common Dairy Products: Yogurt and Kefir
}

\author{
Bilge Taşkın ${ }^{1, a}$, Neriman Bağdatlıoğlu ${ }^{1, b}$ \\ ${ }^{I}$ Department of Food Engineering, Faculty of Engineering, Manisa Celal Bayar University, 45140 Muradiye/Manisa, Turkey,
} *Corresponding author

\begin{tabular}{l|l} 
A R T I C L E I N F O & A B S T R A C T \\
\hline $\begin{array}{l}\text { Research Article } \\
\text { Received : 30/12/2019 } \\
\text { Accepted : 03/04/2020 }\end{array}$ & $\begin{array}{l}\text { During conventional fermentation of milk into yogurt and kefir, changes of antioxidant capacities } \\
\text { (DPPH radical scavenging, ferrous chelating, reducing power, hydrogen peroxide/ } \mathrm{H}_{2} \mathrm{O}_{2} \mathrm{scavenging} \\
\text { activity) and total phenolic content were investigated. Both products showed greater phenolic } \\
\text { content, DPPH radical scavenging, and reducing power activities than was the case of their } \\
\text { unfermented milk forms. But they were unable to scavenge } \mathrm{H}_{2} \mathrm{O}_{2} \text {. Chelating ability of milk increased } \\
\text { by yogurt fermentation but decreased by kefir fermentation. In general, antioxidative capacity of milk } \\
\text { improved throughout conventional yogurt and kefir fermentations and ripening periods (except } \\
\text { chelating ability for kefir and } \mathrm{H}_{2} \mathrm{O}_{2} \text { scavenging). This study is valuable since it evaluates the } \\
\text { antioxidant power of yogurt and kefir produced by traditional fermentation with 5 different } \\
\text { antioxidative approaches. In face of rapidly rising consumer demand for safe, healthy, functional but } \\
\text { natural foods, revealed results might strengthen importance of conventional fermentation process and } \\
\text { highlight the antioxidative contributions of mentioned products. }\end{array}$ \\
$\begin{array}{l}\text { Keywords: } \\
\text { Phtioxidant activity }\end{array}$
\end{tabular}

Phenolic content

Yogurt

Kefir

Fermented milk

\section{Introduction}

Fermented dairy products exhibit various composition, structure, and functional properties depending on the specific starter cultures, milk source, and process type. Yogurt, a medium-acid fermented milk product is fermented by starter cultures $S$. thermophilus and $L$. delbrueckii subsp. bulgaricus and has a viscous gelly structure with smooth flavor. Another acidic and alcoholic fermented milk product, kefir, has a sour cream-like consistency and a strong distinct flavor. Lactic acid bacteria (LAB) species (mostly Lactobacillus, Leuconostoc, Lactococcus) and Acetobacter species live symbiotically with both lactose-fermenting yeasts (Kluyveromyces marxianus) and non-lactose-fermenting yeasts (Saccharomyces spp.) in kefir grains (Surono and Hosono, 2011).

Conversion of milk into fermented milks enhances the nutritional value of intrinsic milk components and brings about components with beneficial physiological effects to consumers. Fermented milk products studied and recognized for their beneficial effects such as antimutagenicity, antitumor and immune-potentiating activity, prevention of pathogens and antioxidative activity (Liu et al., 2005a; Virtanen et al., 2007).

Oxidative damage has significant role in many diseases, so antioxidants can afford prevention on free radical damage and protection against cardiovascular diseases, nucleic acid impairments and other deteriorative processes (Shi et al., 2001). Thus; there is an increasing concern towards natural sources because of toxic and carcinogenic effects of some synthetic antioxidants (Kahl and Kappus, 1993; Liu et al., 2005a). Milk, yogurt and kefir possess antioxidative effects due to many factors such as LAB (Virtanen et al., 2007), superoxide dismutase (SOD), glutathione peroxidase, and catalase enzymes (Lindmark-Mansson and Akesson, 2000), proteins; casein, $\alpha$-lactalbumin, $\beta$-lactoglobulin, lactoferrin (Chiang and Chang, 2005; Sadat et al., 2001), peptides (Farvin et al., 2010a; Sadat et al., 2001), vitamin C, vitamin E and carotenoids (Lindmark-Mansson and Akesson, 2000; Muniandy et al., 2016).

Recently consumers are more willing to consume conventional and natural products due to their regarded 
health benefits. Yogurt and kefir are one of the most consumed and promising fermented foods in the way of preventing oxidative damages. In this respect, the aim of present study was to evaluate the change of antioxidant activity (with a wide range of assay methods) and phenolic quantity during conventional fermentation and ripening of milk to yogurt and kefir.

\section{Materials and Methods}

\section{Materials}

Commercial UHT whole milk $(3.1 \mathrm{~g}$ fat $/ 100 \mathrm{~mL} ; 3 \mathrm{~g}$ protein $/ 100 \mathrm{~mL}$ ) was obtained from a local market in İzmir, Turkey. Plain yogurt (containing S. thermophilus, L. bulgaricus) and kefir grains (containing Lactobacillus kefiri, Lactobacillus acidophilus, Lactobacillus casei, Lactobacillus bulgaricus, Leuconostoc mesentereoides, Lactococcus lactis, Bifidobacterium bifidum, Streptococcus thermophilus, Acetobacter pasteurianus, Kluyveromyces marxianus, Saccharomyces cerevisiae) which were used as starter culture were obtained from Department of Dairy Technology, Ege University, Turkey. All of the chemicals used were of analytical-reagent grade.

\section{Yogurt and Kefir Production}

Yogurt; the starter culture was added by $3 \%(\mathrm{w} / \mathrm{v})$ ratio into UHT milk which was heated to $43-45^{\circ} \mathrm{C}$ and mixed. Inoculated mixture incubated at $43^{\circ} \mathrm{C}$ until $\mathrm{pH}$ was 4.5 (4h). Fermented milk (yogurt) was cooled and kept at $+4^{\circ} \mathrm{C}$. During process six samples were taken (at each fermentation hour and at the end of ripening).

Kefir; kefir grains starter culture was added at the $4 \%$ (w/v) ratio into UHT milk which was brought to $25^{\circ} \mathrm{C}$ and mixed. Inoculated mixture incubated at $20^{\circ} \mathrm{C}$ until $\mathrm{pH}$ was 4.7 (20h). The sample was then kept at $+4^{\circ} \mathrm{C}$ for $12 \mathrm{~h}$ to ripen. At the end of ripening, kefir grains were separated by filtration. During process six samples were taken (at the beginning, at every 5 hours, at the end of ripening).

\section{Total Phenolic Content (TPC) Assay}

TPC was determined by a previously developed method (Singleton et al., 1999). Total phenolic amount was expressed as $\mu \mathrm{g}$ Gallic acid equivalents (GAE) per gram of sample.

\section{DPPH Radical Scavenging Activity Assay}

DPPH radical scavenging capacity determined according to assay of Apostolidis et al. (2007). Radical scavenging capacity results were given as \% inhibition.

\section{$\mathrm{Fe}^{2+}$ Chelating Activity Assay}

The modified methods of Farvin et al. (2010a) and Kim et al. (2005) were used for chelating activity. One $\mathrm{mL}$ extract was mixed with $3.7 \mathrm{~mL}$ deionized water. After that, $0.1 \mathrm{~mL}$ of $2 \mathrm{mM} \mathrm{FeCl}_{2}$ solution was added to mixture and kept for $10 \mathrm{~min}$ at room temperature in dark. Then, $0.2 \mathrm{~mL}$ $5 \mathrm{mM}$ ferrozine solution was added to mixture and kept for $10 \mathrm{~min}$ at room temperature in dark. Absorbance of resulting solution (ferrous iron-ferrozine complex) at 562 $\mathrm{nm}$ was recorded. The $\mathrm{Fe}^{2+}$ chelating activity $(\mathrm{CA} \%)$ was calculated as follows:

$$
\mathrm{CA} \%=\left[\frac{\mathrm{A}_{\text {control }}-\mathrm{A}_{\text {sample }}}{\mathrm{A}_{\text {control }}}\right] \times 100
$$

Eq.1

\section{Reducing Power Assay}

The previously described method (Oyaizu, 1986) was applied. Results shared as absorbance measured at $700 \mathrm{~nm}$. The higher absorbance correlates with greater reducing power.

\section{$\mathrm{H}_{2} \mathrm{O}_{2}$ Scavenging Activity Assay}

It is determined according to assays of Kesenkaş et al. (2011) and Ruch et al. (1989). One mL diluted extract was mixed with $2.4 \mathrm{~mL}$ phosphate buffer ( $\mathrm{pH} 7.4)$ and $0.6 \mathrm{~mL}$ $40 \mathrm{mM} \mathrm{H} \mathrm{O}_{2}$. After $40 \mathrm{~min}$ absorbance was measured at $230 \mathrm{~nm}$. For blank solution; water was used instead of $\mathrm{H}_{2} \mathrm{O}_{2}$ solution. $\mathrm{H}_{2} \mathrm{O}_{2}$ scavenging (SA) determined as below equation, where A means absorbance.

$$
\mathrm{SA} \%=\left[\frac{\mathrm{A}_{\text {control }} \mathrm{A}_{\text {sample }}}{\mathrm{A}_{\text {control }}}\right] \times 100
$$

\section{Statistical Analysis}

Analyses were done triplicate; results were presented as mean \pm standard deviation. For statistical analyses one-way analysis of variance (ANOVA) by SAS software (SAS release 8.1, SAS Institute Inc., North Carolina, USA) was used. $\mathrm{P}$ values below 0.05 were considered as significant by Fisher's LSD test.

\section{Results and Discussion}

\section{Total Phenolic Amount}

As shown in Table 1, TPC of initial milks increased in the courses of both yogurt and kefir fermentations and reached up to their maximum values $(24.01 \mu \mathrm{gGAE} / \mathrm{g}$ yogurt; $38.32 \mu \mathrm{gGAE} / \mathrm{g}$ kefir).

Increase of TPC along fermentation and latter storage time in plain yogurts was also reported by a previous study (Muniandy et al., 2016). During fermentation; proteolysis/hydrolyzing of milk proteins may release active compounds like amino acids with phenolic side chains such as tyrosine (Sadat et al., 2011), which could contribute to TPC (Muniandy et al., 2016). Enzyme activities (i.e. proteinase) may result liberation of such peptides by protein degradation. Also, during fermentation, microbial utilization of phenolic acids (such as ferulic acid, p-cumaric acid) and latter acidification could lead to the production of other phenolic acids such as vanillic and phydroxybenzoic acids before aromatic ring structure was broken down (Blum, 1998).

During yogurt production from soymilk using kefir cultures; soluble phenolic content raised in the first $40 \mathrm{~h}$ and dropped by the last $8 \mathrm{~h}$. The increase was correlated with total peroxidase and laccase activity. Starter culture activity on the soymilk substrate could increase the content of phenolics (McCue and Shetty, 2005). Contrariwise; TPC decreased following fermentation in L. bulgaricus fermented milk (Apostolidis et al., 2007) and kefir made from goat milk (Yilmaz-Ersan et al., 2016). In present study, the decreasing tend could be due to the flux between formation and degradation of polymeric phenolics occur during soymilk bioprocessing by kefir cultures and degradation of phenolics as probable yeast and bacterial antimicrobial detoxification strategies. Another possibility that $\beta$-glucosidase enzyme activity might help in this degradation. 


\section{DPPH Radical Scavenging Activity}

Antioxidants exert DPPH radical scavenging activity based on their hydrogen or electron donating ability, and this reaction is visually noticeable as a change in the color of DPPH (Lim, 2013). Fermentation of milk to both yogurt and kefir enhanced its initial DPPH radical scavenging activity. At the end of yogurt ripening, DPPH radical scavenging activity was increased by $68.53 \%$ and reached to $59.49 \%$ value (Table 1). While a lower increase (by 33.72\%) was observed at the end of kefir ripening.

Antioxidative activity enhancement by fermentation of milk was reported also in previous studies (Apostolidis et al., 2007; Kudoh et al., 2001; Liu et al., 2005a; Wang et al., 2006). With decreasing $\mathrm{pH}$, antioxidative activity predominates and radical formation decreases (LindmarkMansson and Akesson, 2000). As supporting to our findings; DPPH scavenging abilities of goat milk kefir, peanut milk kefir, and fermented skim milk were reported to be significantly greater than those of unfermented milks (Abubakr et al., 2012; Bensmira and Jiang, 2015; YilmazErsan et al., 2016). In addition; up to certain levels of storage periods, increasing scavenging capacities were also determined (Lim, 2013; McCue and Shetty 2005), that was attributed to metabolism of microorganisms in starter cultures. DPPH radical scavenging activity could be affected by the species and counts of LAB and fermentation time.

Not only lactic acid bacterial growth and specific strains of starter cultures (Virtanen et al., 2007) but also other milk factors can generate increased radical scavenging activity like lactoferrin and serum proteins (Chiang and Chang, 2005; Sadat et al., 2001). Antioxidative properties was found to be intrinsic to the peptides' characteristic amino acid sequences, depending on enzyme specificity (Suetsuna et al., 2000; Virtanen et al., 2007), thus they can be enhanced through fractionation or proteolysis. Yogurt exhibited antioxidative properties by some of peptides and free amino acid residues; tyrosine, proline, lysine, in particular hydrophobics; histidine, tryptophan, as well as their sequences (Farvin et al., 2010a; Farvin et al., 2010b; Suetsuna et al., 2000; Virtanen et al., 2007). Consequently, over fermentation period continued lactic acid bacterial growth and increase in extent of proteolysis could improve DPPH scavenging activity in yogurt and kefir samples. Conformably, DPPH radical-linked antioxidant activity and $\alpha$-glucosidase inhibition increased during fermentation, indicating possible positive effect of mobilized phenolics and degraded peptide compounds, in another study (Apostolidis et al., 2007).

\section{$\mathrm{Fe}^{2+}$ Chelating Activity}

$\mathrm{Fe}^{2+}$ catalyzes the lipid peroxidation and generates hydroxyl radical $(\mathrm{OH})$ by Fenton reaction, by which lipid peroxidation is accelerated (Farvin et al., 2010a). Thereby, chelating ferrous iron can enhance antioxidant activity. $\mathrm{Fe}^{2+}$ chelating ability increased by $54.04 \%$ (data were not given) as a result of yogurt fermentation. Inversely, fermentation of milk to kefir reduced chelating ability by $38 \%$ (Fig. 1A and 1B). Ferrous chelating ability showed positive correlations with DPPH scavenging, TPC and reducing power activity in yogurt $(r=0.98,0.91$ and $0.89, \mathrm{P}<0.01$, respectively) but negative correlations in kefir $(\mathrm{r}=-0.90,-0.89$ and $-0.97, \mathrm{P}<0.01$, respectively).
Similarly; Unal et al. reported that, probiotic yogurts exhibited chelating effect more than $50 \%$, and the increase in fermentation time improved chelating activity of probiotic yogurts (Unal et al., 2013). Some other researchers also revealed remarkable ferrous chelating activities for plain and soymilk yogurts as $41.2 \%$ and $56.0 \%$ (Lim, 2013). Studies have reported the iron chelating activity of milk proteins; lactoferrin (LindmarkMansson and Akesson, 2000), casein, whey proteins; serum albumin and high molecular weight fractions of whey (Chiang and Chang, 2005; Tong et al., 2000). In general, asparagine and glutamine with phosphoserine residues and carboxyl and amino groups in the side-chain of the amino acids were known to possess strong affinities for iron (Farvin et al., 2010a; Lim, 2013). Hence, in our study the increment of chelating capacity of yogurt samples may stem from formation of any of these contributors mentioned.

Extracts of LAB strains (i.e. L.casei and L. bulgaricus) also exhibits iron ion chelating skills (Kim et al., 2005; Lin and Yen, 1999). Previously, L. acidophilus increased this ability in soy yogurt (Lim, 2013). Although previously fermentation of milk and soy milk into kefir products did not affect their ferrous ion chelating ability (Liu et al., 2005a; Liu et al., 2005b), in our study kefir possessed significantly lower $\mathrm{Fe}^{2+}$ chelating capacity than milk (Fig. 1B). Abubakr et al. (2012) also reported that, in whey obtained from fermented skim milk by LAB isolates, ferrous chelating activity decreased with fermentation time for 24 to $72 \mathrm{~h}$. They suggested a direct relationship between soluble protein or peptide concentration and chelation capability. Perhaps the amount or structure of proteins (like lactoferrin) or iron-binding fractions (like phosphoryl serine groups) may have changed in the direction of reduction along kefir fermentation. Because lactoferrin concentration was decreased during kefir storage (Kustiawan et al., 2010). Also, binding lactoferrin to some bacteria species, in particular Bifidobacteria spp (Rahman et al., 2007) may pose a possible influence on the reduction. However further studies are needed to clarify these.

\section{Reducing Power}

Reducing power assay used to measure the potential antioxidant capacities of bioactive compounds. During both yogurt and kefir productions; reducing power capacity increased significantly (almost twofold) $(\mathrm{P}<0.05)$ towards the end of ripening periods (Table 2). Reducing power ability was also proved by other studies for plain and soy yogurt (Lim, 2013), and kefir (Liu et al., 2005b). Similar to our findings; it has been reported earlier that (Bensmira and Jiang. 2015; Liu et al., 2005a), fermented kefir products showed higher levels of reducing power capabilities than non-fermented one. Reducing power activities might have stemmed from various enzymatic (catalase, SOD, peroxidase) or non-enzymatic compounds (ascorbate, $\alpha$ tocopherol, glutathione) with potential to reduce oxygen radicals or iron, thereby make it unavailable for oxidative reactions. This power may also be sourced from LAB (Kim et al., 2005; Lin and Yen. 1999; Wang et al., 2006), lactoferrin (Chiang and Chang, 2005) and other milk protein fractions (Farvin et al., 2010a) due to existence of reductions, which can react with free radicals to stabilize 
the radical reactions. It is possible that, increased solubility of lower molecular peptides and the existence of hydrophilic amino acids, such as tyrosine and glutathione, which might have allowed these peptides to get in close contact with the ferrous ions, might improve this antioxidant power (Farvin et al., 2010a, Farvin et al., 2010b).

\section{$\mathrm{H}_{2} \mathrm{O}_{2}$ Scavenging Activity}

$\mathrm{H}_{2} \mathrm{O}_{2}$ scavenging capability was decreased, even an accumulation of hydrogen peroxide was detected at the end of both yogurt and kefir fermentations (Table 2). Some observed fluctuations at intermediates can be hypothesized to arise from the flux between formation and degradation of hydrogen peroxidase in the media.

Despite $\mathrm{H}_{2} \mathrm{O}_{2}$ scavenging abilities of LAB (Kim et al., 2005; Lin and Yen, 1999), some other species or strains of them (i.e. Lactobacillus acidopbilus) can generate this radical (Collins and Aramaki, 1980). Similar to our findings; a significant reduction in the scavenging effect and even some deposition of $\mathrm{H}_{2} \mathrm{O}_{2}$ at the end of fermentation was observed in cow and soy milk kefirs, previously (Kesenkaş et al., 2011, Wang et al., 2006). The reduced $\mathrm{H}_{2} \mathrm{O}_{2}$ scavenging activities can be attributed to formation of $\mathrm{H}_{2} \mathrm{O}_{2}$ by the growth and poliferated starter organisms as suggested before (Marty-Teysset et al., 2000). According to their results, some LAB and bifidobacteria might produce NADH oxidase that forms $\mathrm{H}_{2} \mathrm{O}_{2}$ in oxidizing NADH. In another study (Jimenez et al., 2008), it was found that; obtained fermented dairy products like yogurt, fermented milk and their enriched forms were unable to scavenge $\mathrm{H}_{2} \mathrm{O}_{2}$, due to some enzymatic activity. Some milk enzymes and milk proteins like lactoferrin play role in the scavenging activity of $\mathrm{H}_{2} \mathrm{O}_{2}$ (LindmarkMansson and Akesson. 2000). Previously, it was indicated that activity of superoxide dismutase (SOD) enzyme which catalyzes dismutation of superoxide anion to $\mathrm{H}_{2} \mathrm{O}_{2}$ did not change during kefir fermentation, while the activity of Glutathione peroxidase (GSHPx) which catalysis removal of $\mathrm{H}_{2} \mathrm{O}_{2}$ decreased significantly. Also, catalase activity (heat-labile enzyme that degrade hydrogen peroxide) was undetectable in produced kefirs (Liu et al., 2005a; Liu et al., 2005b). In contrast to those, recently, the addition of whey protein concentrates into probiotic yogurt found to raise the $\mathrm{H}_{2} \mathrm{O}_{2}$ inhibition activity, which explained by higher viable counts of LAB (Unal et al., 2013).

In our study, the reduction in hydrogen peroxide scavenging activity by kefir and yogurt fermentation is thought to be due to the ability of some LAB in starter culture to produce $\mathrm{H}_{2} \mathrm{O}_{2}$ and the presence of SOD enzymes or decrease of GSH-Px/catalase enzyme activities, which affect the production of $\mathrm{H}_{2} \mathrm{O}_{2}$.

When comparing the obtained products at the end of their ripening periods; kefir exhibited statistically higher phenolic content and DPPH scavenging capability but lower chelating capacity than yogurt $(\mathrm{P}<0.05)$. No significant difference found between reducing power abilities $(\mathrm{P}>0.05)$ (as indicated by uppercase letters in Table 1 and 2 and shown in Fig.2). Yogurt and kefir fermented with different process conditions. In addition, dominant microbial communities are variable between these products. The antioxidant activities may vary depending on the food source, starter strains, fermentation temperature, fermentation period, and ripening period. The higher phenolic and antioxidant power of kefir might be resulting from larger variety and quantity of starter cultures in kefir grains as well as longer incubation and ripening time.

Table 1. Total phenolic amount, and DPPH radical scavenging antioxidant activities during yogurt and kefir fermentation and ripening period

\begin{tabular}{l|cccccc}
\hline \multicolumn{7}{c}{ TPC $(\mu \mathrm{gGAE} / \mathrm{g})$} \\
\hline Time $(\mathrm{h})$ & 0 & 1 & 2 & 3 & 4 & 16 \\
Yogurt & $8.45 \pm 1.39^{\mathrm{d}}$ & $13.34 \pm 1.02^{\mathrm{c}}$ & $14.01 \pm 1.02^{\mathrm{c}}$ & $19.23 \pm 1.43^{\mathrm{b}}$ & $18.12 \pm 1.12^{\mathrm{b}}$ & $24.01 \pm 1.90^{\mathrm{aA}}$ \\
Time (h) & 0 & 5 & 10 & 15 & 20 & 32 \\
Kefir & $11.02 \pm 1.14^{\mathrm{e}}$ & $17.13 \pm 1.02^{\mathrm{d}}$ & $19.10 \pm 0.67^{\mathrm{c}}$ & $20.70 \pm 1.39^{\mathrm{bc}}$ & $22.43 \pm 1.54^{\mathrm{b}}$ & $38.32 \pm 1.54^{\mathrm{aB}}$ \\
\hline \multicolumn{7}{c}{ DPPH scavenging $(\%)$} \\
\hline Time (h) & 0 & 1 & 2 & 3 & 16 \\
Yogurt & $35.30 \pm 0.42^{\mathrm{f}}$ & $42.00 \pm 0.32^{\mathrm{e}}$ & $53.65 \pm 0.53^{\mathrm{d}}$ & $56.30 \pm 0.55^{\mathrm{c}}$ & $57.81 \pm 0.61^{\mathrm{b}}$ & $59.49 \pm 0.42^{\mathrm{aA}}$ \\
Time (h) & 0 & 5 & 10 & 15 & 20 & 32 \\
Kefir & $52.31 \pm 0.40^{\mathrm{d}}$ & $63.67 \pm 0.32^{\mathrm{c}}$ & $64.27 \pm 0.69^{\mathrm{c}}$ & $65.79 \pm 0.40^{\mathrm{b}}$ & $66.41 \pm 0.91^{\mathrm{b}}$ & $69.95 \pm 0.40^{\mathrm{aB}}$ \\
\hline
\end{tabular}

1 h: hour. Means in the same line with different letters are significantly different $(\mathrm{P}<0.05)$. Within each analysis parameter; means in the same column with different uppercase letters are significantly different $(\mathrm{P}<0.05)$.

Table 2. Reducing power and hydrogen peroxide scavenging antioxidant activities during yogurt and kefir fermentation and ripening period

\begin{tabular}{l|cccccc}
\hline \multicolumn{7}{c}{ Reducing power (Absorbance) } \\
\hline Time (h) & 0 & 1 & 2 & 3 & 4 & 16 \\
Yogurt & $0.052 \pm 0.001^{\mathrm{e}}$ & $0.060 \pm 0.002^{\mathrm{cd}}$ & $0.057 \pm 0.003^{\mathrm{de}}$ & $0.066 \pm 0.003^{\mathrm{c}}$ & $0.078 \pm 0.005^{\mathrm{b}}$ & $0.10 \pm 0.002^{\mathrm{aA}}$ \\
Time(h) & 0 & 5 & 10 & 15 & 20 & 32 \\
Kefir & $0.056 \pm 0.002^{\mathrm{e}}$ & $0.071 \pm 0.002^{\mathrm{d}}$ & $0.075 \pm 0.003^{\mathrm{cd}}$ & $0.080 \pm 0.003^{\mathrm{bc}}$ & $0.089 \pm 0.004^{\mathrm{b}}$ & $0.11 \pm 0.002^{\mathrm{aA}}$ \\
\hline \multicolumn{7}{c}{$\mathrm{H}_{2} \mathrm{O}_{2}$ scavenging } \\
\hline Time (h) & 0 & 1 & 2 & 3 & 16 \\
Yogurt & $4.00 \pm 0.64^{\mathrm{a}}$ & $2.58 \pm 0.41^{\mathrm{b}}$ & $-1.73 \pm 0.18^{\mathrm{d}}$ & $0.87 \pm 0.27^{\mathrm{c}}$ & $0.95 \pm 0.18^{\mathrm{c}}$ & $-1.07 \pm 0.13^{\mathrm{dA}}$ \\
Time(h) & 0 & 5 & 10 & 15 & 20 & 32 \\
Kefir & $1.27 \pm 0.69^{\mathrm{a}}$ & $0.27 \pm 0.07^{\mathrm{a}}$ & $0.44 \pm 0.03^{\mathrm{a}}$ & $-3.17 \pm 0.91^{\mathrm{bc}}$ & $-2.07 \pm 0.79^{\mathrm{b}}$ & $-4.21 \pm 0.19^{\mathrm{cB}}$ \\
\hline
\end{tabular}



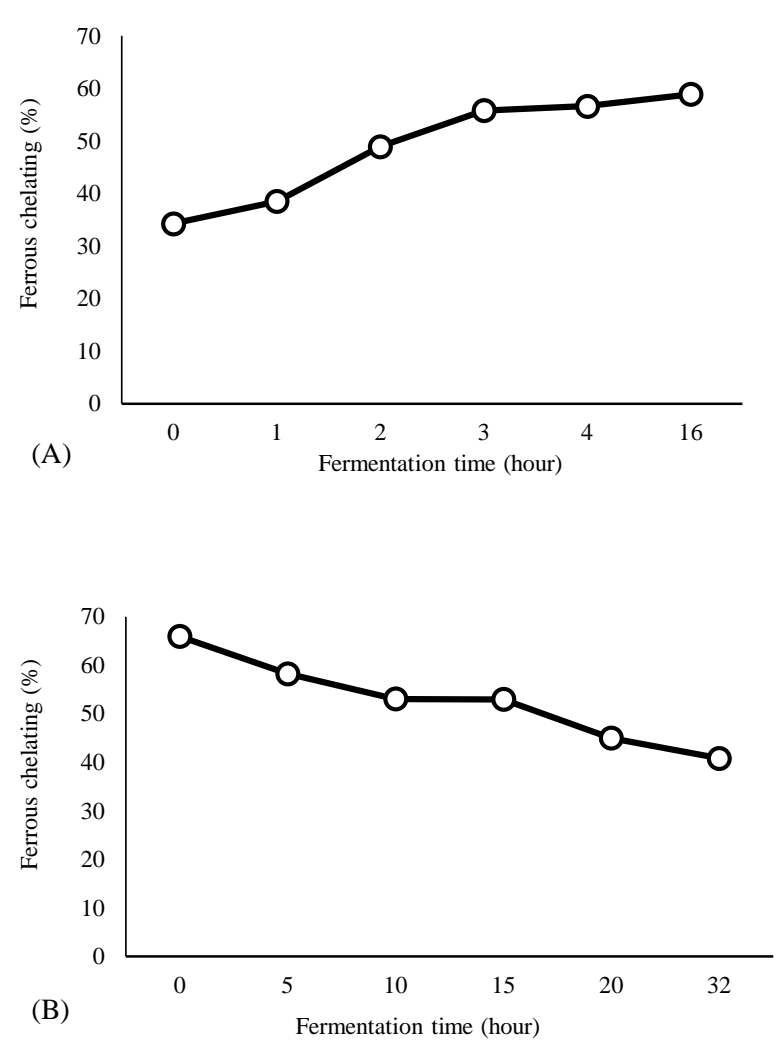

Figure 1. Ferrous chelating activity of yogurt (A) and kefir (B) samples

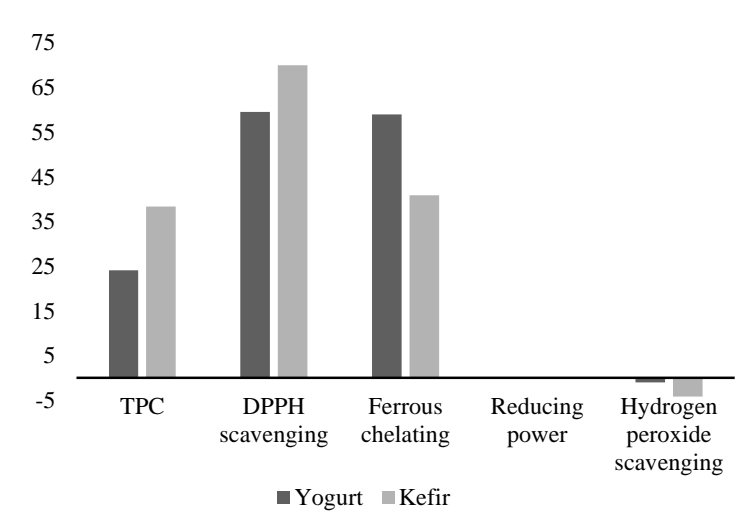

Figure 2. Total phenolic content, DPPH radical scavenging, ferrous chelating and reducing power of yogurt and kefir

\section{Conclusions}

By fermentation process, yogurt and kefir have been shown to have natural protective effects, such as prevention or interruption of radical formation by different antioxidative mechanisms against oxidative damages toward consumer health.

\section{Acknowledgements}

No funding was received.

\section{Conflict of interest}

The authors declare no conflict of interest.

\section{References}

Abubakr MAS, Hassan Z, Imdakim MA, Sharifah NRSA. 2012. Antioxidant activity of lactic acid bacteria (LAB) fermented skim milk as determined by 1,1-diphenyl-2picrylhydrazyl (DPPH) and ferrous chelating activity (FCA). Afr J Microbiol Res, 6: 6358-6364.

Apostolidis E, Kwon YI, Ghaedian R, Shetty K. 2007. Fermentation of milk and soymilk by Lactobacillus bulgaricus and Lactobacillus acidophilus enhances functionality for potential dietary management of hyperglycemia and hypertension. Food Biotechnol, 21: 217-236.

Bensmira M, Jiang B. 2015. Total phenolic compounds and antioxidant activity of a novel peanut based kefir. Food Sci Biotech, 24: 1055-1060.

Blum U. 1998. Effects of microbial utilization of phenolic acids and their phenolic acid breakdown products on allelopathic interactions. J Chem Ecol, 24: 685-708.

Chiang SH, Chang CY. 2005. Antioxidant properties of caseins and whey proteins from colostrums. J Food Drug Anal, 13: 57-63.

Collins EB, Aramaki K. 1980. Production of hydrogen peroxide by Lactobacillus acidophilus. J Dairy Sci, 63: 353-357.

Farvin KHS, Baron CP, Nielsen NS, Jacobsen C. 2010a. Antioxidant activity of yoghurt peptides: Part 1 -in vitro assays and evaluation in $\omega-3$ enriched milk. Food Chem, 123: 1081-1089.

Farvin KHS, Baron CP, Nielsen NS, Otte J, Jacobsen C. 2010b. Antioxidant activity of yoghurt peptides: Part 2 - Characterisation of peptide fractions. Food Chem, 123: 1090-1097.

Jimenez AM, Murcia MA, Parras P, Martinez-Tome M. 2008. On the importance of adequately choosing the ingredients of yoghurt and enriched milk for their antioxidant activity. Int J Food Sci Tech, 43: 14641473.

Kahl R, Kappus H. 1993. Toxicology of the synthetic antioxidants BHA and BHT in comparison with the natural antioxidant vitamin E. Z. Lebensm Unters Forsch, 196: 329-38.

Kesenkaş H, Dinkçi N, Seçkin K, Kınık Ö, Gönç S. 2011. Antioxidant properties of kefir produced from different cow and soy milk mixtures. J Agr Sciences, 17: 253259.Kim HS, Chae HS, Jeong SG, Ham JS, Im SK, Ahn CN, Lee JM. 2005. Antioxidant activity of some yogurt starter cultures. Asian Austral J Anim, 18: 255-258.

Kudoh Y, Matsuda S, Igoshi K, Oki T. 2011. Antioxidative peptide from milk fermented with Lactobacillus delbrueckii ssp bulgaricus IFO13953. J Jpn Soc Food Sci Technol, 48: 44-50.

Kustiawan E, Purnomo H, Radiati LE. 2010. The effect of heating and postfermentation on lactoferrin of fresh and kefir goat milk. J Ilmu dan Teknol Has Ternak, 5: 1-8.

Lim SM. 2013. Microbiological, physicochemical, and antioxidant properties of plain yogurt and soy yogurt. Korean J Microbiol, 49: 403-414.

Lin MY, Yen CL. 1999. Antioxidative ability of lactic acid bacteria. J Agr Food Chem, 47: 1460-1466.

Lindmark-Mansson H and Akesson B. 2000. Antioxidative factors in milk. Br J Nutr, 84: 103-110. 
Liu JR, Chen MJ, Lin CW. 2005a. Antimutagenic and antioxidant properties of milk-kefir and soymilk-kefir. J Agric Food Chem, 53: 2467-2474.

Liu JR, Lin YY, Chen MJ, Chen LJ, Lin CW. 2005b. Antioxidative activities of kefir. Asian-Australas J Anim Sci, 18: 567-573.

Marty-Teysset C, De La Torre F, Garel JR. 2000. Increased production of hydrogen peroxide by Lactobacillus delbrueckii subsp. bulgaricus upon aeration: Involvement of an NADH oxidase in oxidative stress. Appl Environ Microbiol, 66: 262-267.

McCue PP, Shetty K. 2005. Phenolic antioxidant mobilization during yogurt production from soymilk using kefir cultures. Process Biochem, 40: 1791-1797.

Muniandy P, Shori AB, Baba AS. 2016. Influence of green, white and black tea addition on the antioxidant activity of probiotic yogurt during refrigerated storage. Food Packag Shelf Life, 8: 1-8.

Oyaizu M. 1986. Studies on products of browning reactions: Antioxidative activities of browning products of browning reaction prepared from glucosamine. Jpn J Nutr, 44: 307-315.

Ruch RJ, Cheng S, Klaunig JE. 1989. Prevention of cytotoxicity and inhibition of intracellular communication by antioxidant catechins isolated from Chinese green tea. Carcinogenesis, 10: 1003-1008.

Sadat L, Cakir-Kiefer C, Negue MN, Gaillard JL, Girardet, JM, Miclo M. 2011. Isolation and identi fication of antioxidative peptides from bovine $\alpha$-lactalbumin. Int Dairy J, 21: 214-221.

Shi H, Noguchi N, Niki E. 2001. Introducing natural antioxidants. In: Pokorny J, Yanishlieva N, Gordon M (ed). Antioxidants in food: practical applications. Cambridge, CRC Press, 147-157.
Singleton VL, Orthofer RM and Ramuela-Raventos RM. 1999. Analysis of total phenols and other oxidation substrates and antioxidants by means of Folin Ciocalteu reagent. Methods Enzymol, 299: 152-178.

Suetsuna K, Ukeda H, Ochi H 2000. Isolation and characterization of free radical scavenging activities peptides derived from casein. J Nutr Biochem, 11: 128-131.

Surono IS, Hosono A. 2011. Types and standards of identity. Vol. 2, In: John WF, Patrick FF, Paul LHM (ed). Encyclopedia of Dairy Sciences. London, Academic Press Elsevier Inc, 470-476.

Tong LM, Sasaki S, McClements DJ, Decker EA. 2000. Mechanisms of the antioxidant activity of a high molecular weight fraction of whey. J Agric Food Chem, 48: 1473-1478.

Unal G, El SN, Akalin AS, Dinkci N. 2013. Antioxidant activity of probiotic yoghurt fortified with milk protein based ingrediants. Ital J Food Sci, 25: 63-69.

Rahman M, Kim WS, Ito T, Kumura H, Shimazaki K. 2007. Visualization of bovine lactoferrin binding to bifidobacteria. Bioscience Microflora, 26: 75-79.

Virtanen T, Pihlanto A, Akkanen S, Korhonen H. 2007. Development of antioxidant activity in milk whey during fermentation with lactic acid bacteria. J Appl Microbiol, 102: 106-115.

Wang YC, Yu RC, Chou CC. Antioxidative activities of soymilk fermented with lactic acid bacteria and bifidobacteria. Food Microbiol, 23: 128-135.

Yilmaz-Ersan L, Ozcan T, Akpinar-Bayizit A, Sahin S. 2016. The Antioxidative capacity of kefir produced from goat milk. Int J Chem Eng Appl, 7: 22-26 